\title{
Design Considerations of a Monitoring System of a Farm for Energy Efficiency Purposes
}

\author{
Karen Moposita*, Xavier Noboa-López*, Jean-Michel Clairand, Member, IEEE*, \\ Marco Briceño-León*, Guillermo Escrivá-Escrivá ${ }^{\dagger}$, and Antonio-Marco Pantaleo ${ }^{\ddagger}$ \\ *Facultad de Ingenería y Ciencias Agropecuarias, Universidad de las Américas, 170122, Quito, Ecuador, \\ E-mail: karen.moposita@udla.edu.ec,xavier.noboa@udla.edu.ec,jean.clairand@udla.edu.ec,marco.briceno@udla.edu.ec \\ †Institute for Energy Engineering, Universitat Politècnica de València, 46022, Valencia, Spain, E-mail: guieses@die.upv.es \\ ${ }_{\ddagger}^{\ddagger}$ Department of Agro-environmental Sciences, University of Bari, 70125, Bari, Italy, E-mail: antonio.pantaleo@uniba.it
}

\begin{abstract}
The monitoring of industry processes can optimize the use of resources and improve its efficiency. In dairy farms, several parameters from the processes must be monitored. This paper proposes the design of a monitoring system for a farm that produces dairy products and jams. Several similar studies are analysed. Based on this, and on the farm characteristics, a novel design is developed. The principal benefits of the system are also exposed.
\end{abstract}

Keywords-Dairy Industry, Energy Efficiency, Monitoring System, Sensors

\section{INTRODUCTION}

The significant growth of energy demand, increasing environmental concerns are pushing governments to develop new technologies to make better use of energy resources. Therefore, energy management systems (EMSs) emerge as a solution for mitigating these energy concerns. Several novel methodologies to use energy efficiently have been proposed, such as demand response (DR) or demand-side management (DSM), which incentivize customers economically to reduce consumption during periods of critical grid conditions[1].

So far, industrial and commercial customers have been the most active customers in such programs because of their high potential to reduce energy consumption and to manage the load [2]. However, other customers, such as agricultural and small food processing companies have been taken less into consideration due to their low electric load and their rigid activities. In a future smart grid, these customers will play a significant role, considering their aggregated load.

Some studies have been reported in the literature on energy optimization methods in different meal industries. For example, in [3] the use of flexibility for DR is studied in the meat industry. This work is complemented by [4], where the economic and environmental factors are evaluated, demonstrating proper financial savings and $\mathrm{CO}_{2}$ avoided in the atmosphere. The authors of [5] propose an air ventilation strategy for quantifying energy savings for a cheesemaking plant, resulting in electricity savings. In [6], the energy efficiency and renewable generation opportunities are evaluated in a small scale dairy farm in Canada. The authors of [7] present an energy economic analysis and optimization for bread baking.
In [8], the techno-economic analysis of a waste-heat recovery system for an intermittent coffee-roasting process is proposed in an Italian coffee processing plant.

In Ecuador, the most important source of growth domestic product (GDP) corresponds to agriculture with $14 \%$ [9], with a significant increase each year. Furthermore, small scale agriculture corresponds to $55 \%$ of the total. This sector consumes $4 \%$ of the total energy [10]. However, no existing energy efficiency programs have been yet implemented in this sector. In this context, there is a significant potential for implementing energy efficiency programs in farms. But, for this, it is necessary to study appropriately different parameters that influence in the production of agro-food products, including temperature, power, pressure, which can have a crucial impact on optimizing energy consumption.

Actually, with the development of Information and Communication Technologies (ICT), and with the high performance of new sensors, it is possible to monitor these parameters and others. In this sense, remote monitoring systems for farms need to be installed for energy management purposes. Several works have developed sensor networks and monitoring systems, but to the knowledge of the authors, a monitoring system for a farm has not been studied. The aim of this paper is to propose a design of a monitoring system in a farm that produces dairy products and jams.

The rest of the paper is organized as follows: Section II presents a brief overview of monitoring systems. Section III presents the case study. Section IV presents the design considerations. Finally, Section V highlights the main conclusions and future work.

\section{BACKGROUND}

The background is divided in three categories of related works: communication systems, sensor networks and monitoring systems.

\section{A. Communication Systems}

Communication systems are crucial to sending information from the information source to the user. 
In [11], a novel statistical methodology for the performance analysis of wM-Bus networks for smart metering is proposed. A wM-Bus is used to have a low power consumption by the radio transmission and reaches a better coverage; therefore smart metering can be used as the best application. The case study considers received signal stenght indication (RSSI) adapting the meter transmission power in the quality of the signal using the Google Maps software to verify how the signal was obtained in the whole map within the city. This analysis was carried out in Italy. However, smart meters are featured with short range antennas, limiting the coverage range. The authors of [12] present a system that monitors a fleet of educational buildings. The system presented can be used to develop and offer new solutions based on applications that can be used for educational purposes or to manage the energy efficiency of the building. However, only the energy monitoring was considered and not environmental monitoring. In [13], three different types of wireless sensor networks (WSNs) are analyzed considering the energy consumption for monitoring a tomato greenhouse. The three WSNs are ZigBee with a star topology, ZigBee with mesh topology, and WiFi with access point topology, resulting in the ZigBee (star topology) and WiFi networks in lower consumption. However, distance communication is small due to the batteries size. The authors of [14] study a lightweight authenticated communication scheme for the smart grid. The security analysis shows that the transmission of the message between the smart meters and the gateway of the neighborhood can be done in a confidential and authenticated manner. Besides, compared to other existing schemes, the performance analysis shows that the proposed scheme has a lower cost of storage and communication.

\section{B. Sensor Network}

The authors [15] present the feasibility of a Hi-Bi fiber loop mirror with a $\mathrm{Hi}-\mathrm{Bi}$ fiber output probe for temperature measurement. They demonstrate that this technology has a high accuracy for temperature measurement, making it proper for remote sensing applications. In the same line, in [16], a surface temperature sensor is developed for energy efficiency purposes in buildings.

By other hand, the authors of [17] studied energy sensors in a cost-effective smart device, which is installed in a Schuko socket. This sensor allows monitoring the energy consumption in real-time.

\section{Monitoring Systems}

Monitoring systems are crucial to evaluate various variables in real-time. In [18] present a monitoring system, which assess energy consumption, thermal performance, and indoor air quality. With this monitoring system, it is possible to evaluate building energy performance. In the same line, the authors of [19] propose the energy monitoring of a building, using the Unfolding or Multiway Principal Component Analysis. In [20] a load disaggregation algorithm is studied for smart meter

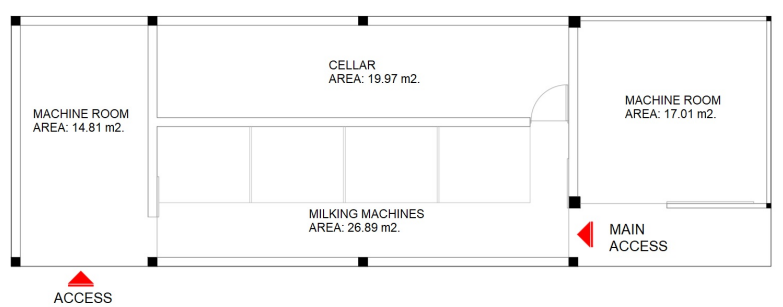

Fig. 1. Plan of "Granja 1".

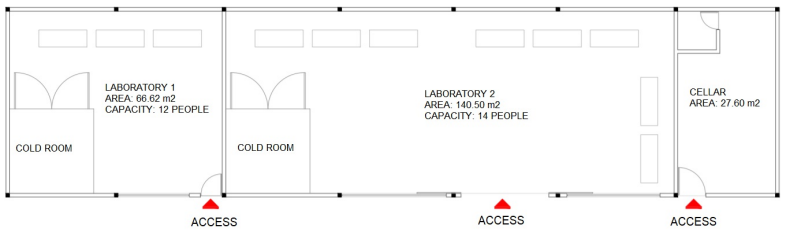

Fig. 2. Plan of "Granja 2".

sensor data. This algorithm is based on non-intrusive appliance monitoring, which provides accurate data.

\section{CASE STUdy}

\section{A. Nono farm}

The farm belongs to Universidad de las Américas - Ecuador. It is situated in the parish of Nono, which is situated $22 \mathrm{~km}$ from Quito, with a temperature fluctuating between $14^{\circ} \mathrm{C}$ and $16^{\circ} \mathrm{C}$, and is 2800 meters above sea level. The farm has 44.6 hectares where are developed agricultural products, training, research, and projects. The main activities of the Nono farm are listed as follow:

- Livestock production of lesser species

- Management of pigs, sheep and cattle livestock

- Agricultural production and post-harvest

- Food processing

Some plans for the future of the farm includes having $100 \%$ organic products, and there is an ongoing process for cleaning the soil in order to have products with a greater added value.

The monitoring system will be implemented in the facility named "Granja 1" and in the facility named "Granja 2", in which their plans are depicted in Fig. 1 and Fig. 2.

\section{B. Description of the energy consuming devices}

In the farm, especially dairy products and jams are produced. The key components that consume energy in production are milking machines, boiler, refrigetaror, mixer, and lights. Therefore, the operation of these components are analyzed in order to identify opportunities for reducing energy consumption.

In the facility "Granja 1", the herd is milked twice per day and includes the milking machines, and some lights. The milking machine is shown in Fig.3.

In the facility "Granja 2", the milk and fruits are delivered in order to produce the end products. Granja 2 includes lights, 


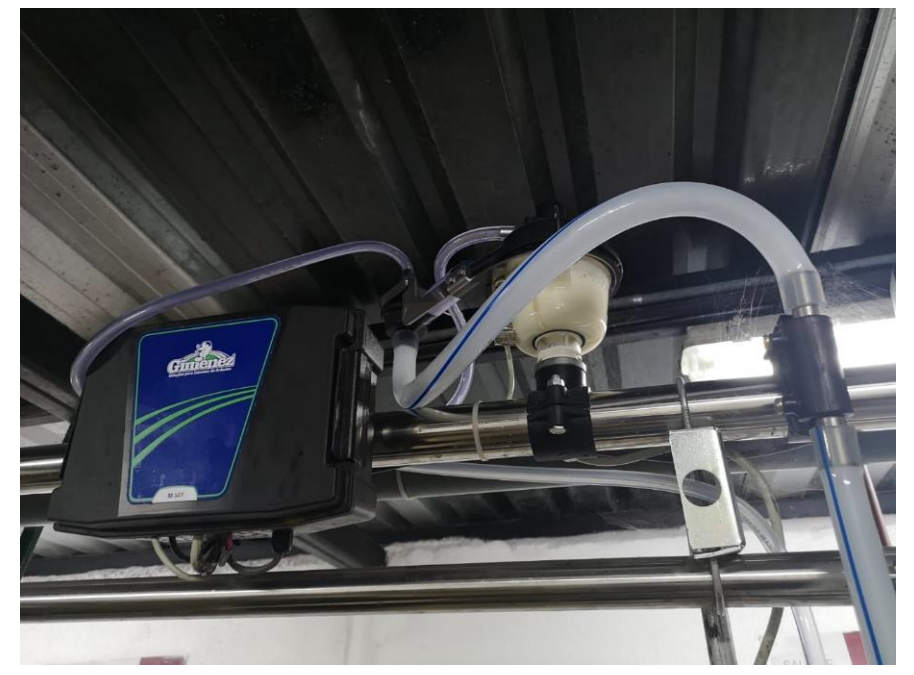

Fig. 3. Milking Machine.

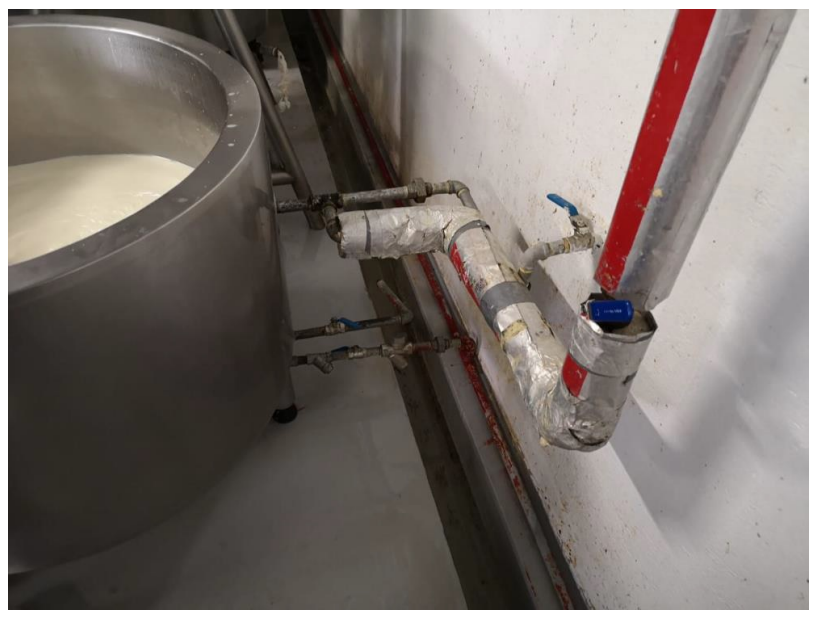

Fig. 4. Boiler.

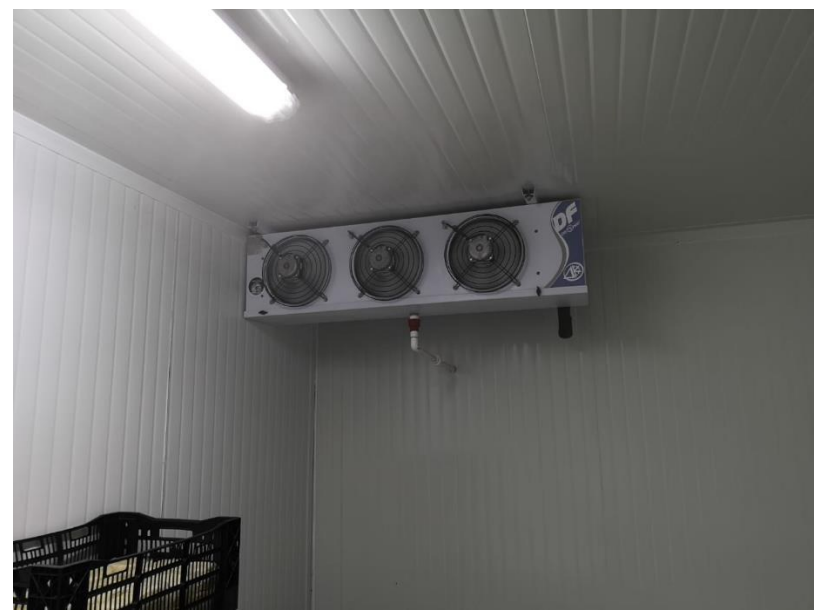

Fig. 5. Cold Room with Ventilation.

the boiler, and two cold rooms with refrigeration. The boiler is shown in Fig.4, and Fig.5.

\section{DESIGN CONSIDERATIONS}

In this section, the design considerations for all the studied parameters are detailed.

\section{A. Temperature}

It is considered that one temperature sensor has to be installed outside the facilities to measure the ambient temperature. Another sensor has to be installed inside the facility in order to evaluate heat flows. According to the Fourier's law of thermal conduction:

$$
\mathbf{q}=k . \nabla T
$$

where: $\mathbf{q}$ is the vector of local heat flux density $\left[\mathrm{W} \cdot \mathrm{m}^{-2}\right.$, $k$ is the material's conductivity $\left[\mathrm{W} .{ }^{-1} \cdot \mathrm{K}^{-1}\right]$, and $\nabla T$ is the temperature gradient $\left[\mathrm{K} \cdot \mathrm{m}^{-3}\right]$. This means that the temperature varies with distance. Therefore, various sensors have to be installed in the cold room to evaluate the refrigeration losses, so 4 sensors are considered a proper number. It is necessary to transform the data as an output voltage. Thus, considering that the sensor has to support cold conditions, and have not oxidating requirements, the thermocouple type $\mathrm{K}$ is selected.

\section{B. Electric Power}

The electric power sensors could be placed in each of the machines that use electricity, such as the refrigeration, the milking machine, and dairy processors. It is considered that the power information has to be sent by Zigbee. Furthermore, the different refrigeration and processing machines, and the lights are directly connected to the plugs. Hence, the Zigbee smart power meter wall sockets are selected to monitor electric power.

\section{Humidity}

For humidity sensors, it is reasonable to place them inside the refrigeration rooms, in order to maintain control of the products, without affecting them. In addition, it is crucial to place humidity sensors inside the room, processing machines, and outside the facility. In the refrigeration rooms, the products, like cheese, start to lose weight due to evaporation, which affects humidity existing in the environment where it is stored, and in case there is a lot of humidity, the micro-organisms will spread much more easily and this is common in places with high humidity. Thus, these sensors are important to monitor the quality of the products while performing energy efficiency activities, such as turning off for a moment the refrigeration.

\section{Communication Systems}

The two facilities are separated by 200 meters. They are also situated from 300 meters from the farmhouse, where a Wi-Fi network is available. The information provided from the farm needs to been sent in real-time to the University, which is situated from $20 \mathrm{~km}$, in Quito, and the information has to be stored in a database. Bluetooth technology was discarded because of the limited coverage radius. Then, Zigbee technology was selected in comparison with Bluetooth because it is more economical and the mesh topology that can be 


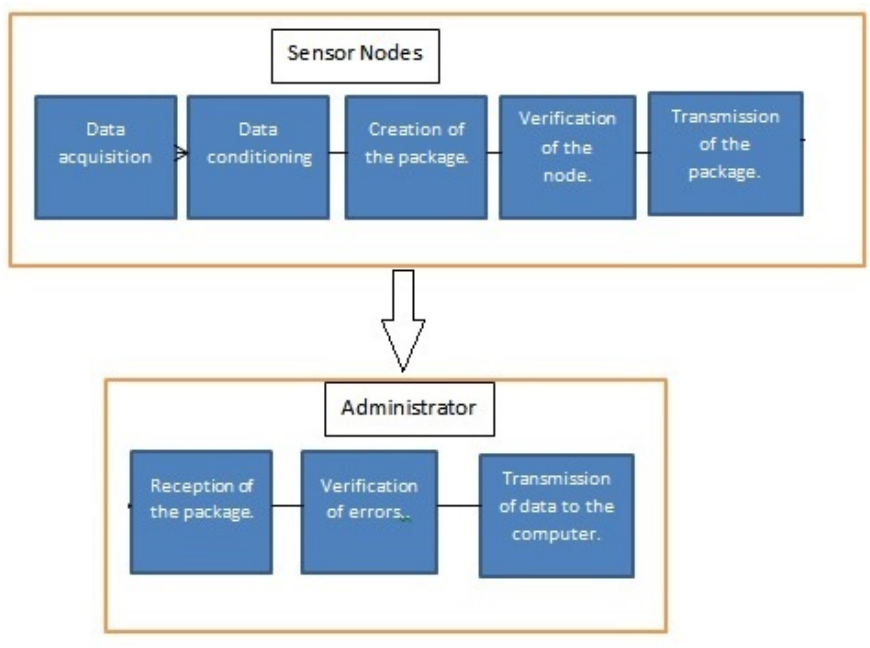

Fig. 6. Flowchart of Monitoring System.

generated with Zigbee presents considerable energy savings and better transmission in the data due to the establishment of multi-path routes with alternative routes in case that any node is blocked. The Zigbee will be connected to the Wi-Fi network through a BlueBox Smart Datalogger system, which is a sophisticated Gateway between networks Zigbee and Modbu. 6.

The flowchart of the monitoring system is depicted in Fig.

The sensor network is divided in four sensors, which are detailed next:

- Node 1: Milking room

- Node 2: Dairy products processing

- Node 3: Jams processing

- Node 4: Ventilation and lighting

These nodes are divided in this way, since the first one is distanced from the last two, therefore, it will be a node excluded from the others. For the case of the last two nodes, the same sensors are needed in same areas, but since they are different processes they have to be monitored separately. The innovative contribution lies in the use of two communication methods, in order to exploit the best of each one. These nodes will be connected to a coordinator, which will be directly connected to the room farm $\mathrm{Wi}-\mathrm{Fi}$, to transfer the data directly to the University. The architecture of the proposed system is illustrated in Fig.7.

\section{E. Devices Control}

In addition to the monitoring of consumption and process variables, one of the most important measures to improve the energy efficiency of a facility is to implement the scheduling of certain actions on the process automatically [21]. Thus, for example, the connection or disconnection of an air conditioning unit, the opening or closing of a cold circuit valve etc. can be controlled. Therefore, in the proposed system, a PLC is installed. The PLC activates each one of its outputs and implies a certain action on the system. It is the server,

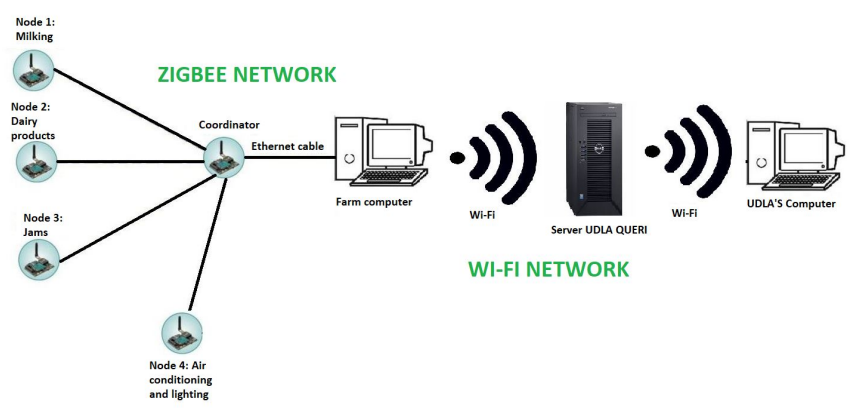

Fig. 7. Architecture of the proposed system.

through a planning software, that is in charge of writing the order in the PLC and the PLC already executes it locally. Actions must not be performed by timers or personal because it implies inefficiencies or errors.

\section{Main AdVANTAges OF THE PROPOSED MONitoring SYSTEM}

\section{A. Boiler Efficiency}

Steam is the most important use that is given to the energy in regard to the dairy industry, this will be used in heating applications for the processes of: pasteurization, cooking and evaporation. The vast majority of steam systems use natural gas and coal as fuel for the boiler, and this improves the efficiency of the steam system and also helps to reduce excessive energy costs.

With a proper monitoring of the boiler characteristics it is possible to improve:

- Reduce Excess Air: since this is achieved by reducing the emission of gases such as nitrogen oxides in the interior of the boiler, which ensures that there is not so much heat loss and what improves the efficiency of the boiler.

- Flue Gas Monitoring: it is possible to notice air infiltrations in the combustion of the cauldron.

- Regularly Record the Flue Gas Temperature: it is a practice to draw trends of how the cauldron works and what temperature the flame handles, to regulate it.

- Properly Sized Boiler Systems: the boiler can be dimensioned depending on the required purposes.

- Boiler Maintenance: the boiler must be given adequate maintenance continuously, being a preventive maintenance that will save operating costs.

- Condensate Return: the return of condensate would reduce the use of energy

- Direct Contact Water Heating: water heaters that are in direct contact can operate by atmospheric pressure, which will prevent safety risks.

\section{B. Electricity Efficiency}

The energy consumption with regard to refrigeration can be increased by the heat entering through the doors of the refrigerator chambers. To this end, the automatic closing of doors or an alarm system can be considered. Lights and fans can also add to the heat load and for this you can use sensors 
or timers so that the lights are used only when necessary. Compressed air leaks can be detected by pressure sensors.

\section{CONCLUSIONS}

This paper presents the design of a novel monitoring system of a farm that produces dairy products and jams. The monitored parameters are temperature, electricity power, steam pressure of a boiler, and humidity. The topology and architecture is studied, and compared to similar works in the literature. The benefits of the proposed system are then explained, considering the thermal and electric efficiency.

In a future work, the implemented monitoring system will be presented with the different parameters curves.

\section{ACKNOWLEDGEMENTS}

This work was supported by Universidad de las Américas Ecuador under project SIS.JCG.19.01. The authors would like to thank Mónica Guevara, Andrea Maldonado, and Francisca Martínez from Universidad de las Américas - Ecuador for their valuable help and information.

\section{REFERENCES}

[1] M. C. Bozchalui, C. A. Cañizares, and K. Bhattacharya, "Optimal operation of climate control systems of produce storage facilities in smart grids," IEEE Trans. Smart Grid, vol. 6, no. 1, pp. 351-359, 2015.

[2] M. C. Bozchalui, C. A. Cañizares, and K. Bhattacharya, "Optimal energy management of greenhouses in smart grids," IEEE Trans. Smart Grid, vol. 6 , no. 2, pp. 827-835, 2015.

[3] M. Alcázar-Ortega, C. Álvarez-Bel, G. Escrivá-Escrivá, and A. Domijan, "Evaluation and assessment of demand response potential applied to the meat industry," Appl. Energy, vol. 92, pp. 84-91, 2012.

[4] M. Alcázar-Ortega, C. Álvarez-Bel, A. Domijan, and G. EscriváEscrivá, "Economic and environmental evaluation of customers' flexibility participating in operation markets: Application to the meat industry," Energy, vol. 41, no. 1, pp. 368-379, 2012. [Online]. Available: http://dx.doi.org/10.1016/j.energy.2012.03.003

[5] P. S. Mirade, B. Perret, H. Guillemin, D. Picque, B. Desserre, M. C. Montel, and G. Corrieu, "Quantifying energy savings during cheese ripening after implementation of sequential air ventilation in an industrial cheesemaking plant," Energy, vol. 46, no. 1, pp. 248-258, 2012. [Online]. Available: http://dx.doi.org/10.1016/j.energy.2012.08. 026

[6] C. Houston, S. Gyamfi, and J. Whale, "Evaluation of energy efficiency and renewable energy generation opportunities for small scale dairy farms: A case study in Prince Edward Island, Canada," Renew. Energy, vol. 67, pp. 20-29, 2014.

[7] D. Papasidero, S. Pierucci, and F. Manenti, "Energy optimization of bread baking process undergoing quality constraints," Energy, vol. 116, pp. 1417-1422, 2016. [Online]. Available: http://dx.doi.org/10.1016/j. energy.2016.06.046

[8] A. M. Pantaleo, J. Fordham, O. A. Oyewunmi, P. De Palma, and C. N. Markides, "Integrating cogeneration and intermittent waste-heat recovery in food processing: Microturbines vs. ORC systems in the coffee roasting industry," Appl. Energy, vol. 225, no. January, pp. 782-796, 2018. [Online]. Available: https://doi.org/10.1016/j.apenergy. 2018.04.097

[9] B. C. del Ecuador, "Reporte de cuyuntura sector agropecuario," 2013. [Online]. Available: https://contenido.bce.fin.ec/documentos/PublicacionesNotas/ Catalogo/Encuestas/Coyuntura/Integradas/etc201604.pdf

[10] MEER, "Hacia una matriz energética diversificada en Ecuador," 2013. [Online]. Available: http://biblioteca.olade.org/opac-tmpl/Documentos/ cg00344.pdf

[11] A. Pietrosanto, M. Carratu, P. Sommella, M. Ferro, and V. Paciello, "Performance Analysis of wM-Bus Networks for Smart Metering," IEEE Sens. J., vol. 17, no. 23, pp. 7849-7856, 2017.
[12] D. Amaxilatis, O. Akrivopoulos, G. Mylonas, and I. Chatzigiannakis, "An IoT-based solution for monitoring a fleet of educational buildings focusing on energy efficiency," Sensors (Switzerland), vol. 17, no. 10, pp. 1-15, 2017.

[13] M. Erazo-Rodas, M. Sandoval-Moreno, S. Muñoz-Romero, M. Huerta, D. Rivas-Lalaleo, and J. L. Rojo-álvarez, "Multiparametric monitoring in equatorian tomato greenhouses (III): Environmental measurement dynamics," Sensors (Switzerland), vol. 18, no. 8, pp. 1-36, 2018.

[14] Y. Liu, C. Cheng, T. Gu, T. Jiang, and X. Li, "A Lightweight Authenticated Communication Scheme for Smart Grid," IEEE Sens. J., vol. 16, no. 3, pp. 836-842, 2016.

[15] J. Zhang, P. Zhao, Q. Rong, Z. Feng, Y. Weng, M. Hu, X. Qiao, R. Wang, Y. Ma, and T. Guo, "Highly-Sensitive Temperature Sensor Using a Hi-B Fiber Tip Probe," IEEE Sens. J., vol. 12, no. 6, pp. 2077-2080, 2012.

[16] L. Mota, A. Mota, C. Pezzuto, M. Carvalho, M. Lavorato, L. Coiado, and E. Oliveira, "Development of a surface temperature sensor to enhance energy efficiency actions in buildings," Sensors (Switzerland), vol. 18, no. 9,2018

[17] R. Morales, F. J. Badesa, N. García-Aracil, C. Perez-Vidal, and J. M. Sabater, "Distributed smart device for monitoring, control and management of electric loads in domotic environments," Sensors (Switzerland), vol. 12 , no. 5, pp. 5212-5224, 2012.

[18] T. Sharmin, M. Gül, X. Li, V. Ganev, I. Nikolaidis, and M. Al-Hussein, "Monitoring building energy consumption, thermal performance, and indoor air quality in a cold climate region," Sustain. Cities Soc., vol. 13, pp. 57-68, 2014. [Online]. Available: http://dx.doi.org/10.1016/ j.scs.2014.04.009

[19] L. Burgas, J. Melendez, J. Colomer, J. Massana, and C. Pous, "Multivariate statistical monitoring of buildings. Case study: Energy monitoring of a social housing building," Energy Build., vol. 103, pp. 338-351, 2015.

[20] G. C. Koutitas and L. Tassiulas, "Low Cost Disaggregation of Smart Meter Sensor Data," IEEE Sens. J., vol. 16, no. 6, pp. 1665-1673, 2016.

[21] G. Escrivá-Escrivá, "Basic actions to improve energy efficiency in commercial buildings in operation," Energy Build., vol. 43, no. 11, pp. 3106-3111, 2011. 